Zenaide Providello Moysés

\title{
Efeito da fluoxetina na \\ reabsorção de água pelo rim
}

Dissertação apresentada à Faculdade de Medicina da Universidade de São Paulo para obtenção do título de Mestre em Ciências

Área de concentração: Nefrologia

Orientador: Dr. Antonio José Barros Magaldi

São Paulo

2006 
Este trabalho foi realizado no Laboratório de Pesquisa Básica (LIM 12) da Faculdade de Medicina da Universidade de São Paulo. 


\section{DEDICATÓRIA}

A meus pais Geraldo e Zira e minha avó Anna

(in memorian)

Aos meus irmãos Cezira, Décio, Neusa, Deonisia e Elisangela.

Aos meus sobrinhos William, Alessandra, Celso, Wattson, Priscila, Eline, Felipe e Natasha.

Pelo apoio e compreensão sem eles nada disso seria possível. 


\section{AGRADECIMENTOS}

Ao Dr. Antonio José Barros Magaldi, por ser além de meu orientador um grande amigo, que me apoiou nos momentos que mais precisei, por sua integridade, competência e paciência na orientação e supervisão em todo o meu aprendizado.

Ao Prof. Antonio Carlos Seguro, responsável pelo Laboratório de Pesquisa Básica LIM-12, pelas sugestões e contribuição.

A Kátia Regina César e Lúcia Harumi Kudo, pela amizade e aprendizado da técnica de microperfusão.

Ao graduando Fausto K. Nakandakari e a biologista Ana Carolina de Bragança, por sua amizade e contribuição na realização dos experimentos.

Ao Luís Fernando Carvalho de Menezes por sua disponibilidade, apoio, amizade e aprendizado da técnica de Western Blotting. 
À Cecília da Conceição Costa, por sua amizade e dedicação com os animais de laboratório.

Ao Nivaldo Francisco da Silva e Eloá de Sousa Neves, por sua amizade e apoio administrativo.

Aos técnicos de câmara escura do Instituto de Radiologia da Faculdade de Medicina da USP.

As funcionárias Márcia Ribalta e Mirela A.R. Santinho do laboratório de Nefrologia do ICHC, pelas dosagens.

A funcionária Valéria Lando do LIM-42, pelas dosagens do ADH.

Aos colegas e funcionários do LIM-12, por sua amizade, particularmente ao graduando Adison C. Rodrigues Jr. e a técnica de nível superior Ivone I.M. da Fonseca, pelo conhecimento em informática.

Aos colegas e funcionários do LIM-16, particularmente ao pósgraduando Humberto Dellê pelo apoio.

Aos colegas e funcionários do LIM-10, pelo apoio técnico e amizade, particularmente a Isabel C.D. Ribeiro e Flavia do Carmo. 
Ao Biotério Central da Faculdade de Medicina da USP, pelo fornecimento dos animais.

A Biblioteca da Faculdade de Medicina da Universidade de São Paulo, pela orientação.

Ao Departamento de Nefrologia da Faculdade de Medicina da USP.

À CNPq, bolsa (130797/04-9), pelo apoio financeiro. 
Moysés ZP. Fluoxetine effect on kidney water absorption (dissertation). São Paulo: "Faculdade de Medicina, Universidade de São Paulo"; 2006. 43p.

The pathogenesis of the hyponatremia after Fluoxetine(Fx) supply in elderly is not well understood. This event has been attributed to an inappropriate antidiuretic hormone secretion although the vasopressin enhanced plasma level has not been demonstrated yet in these pacients. Thus, this experiment was designed to investigate the effect of Fx on the kidney and more specifically if it would have a direct effect in the inner medullary collecting duct (IMCD) from normal rats: 1) in vivo study- 10 rats were supplied daily with i.p. injections of Fx $10 \mathrm{mg} / \mathrm{kg}$. After five days, the rats were sacrificed and blood and kidneys were collected. 2) in vitro studya) Immunobloting studies for AQP2 protein expression, in IMCD from supplied rats and in IMCD tubules suspension from 10 normal rats incubated with $\mu \mathrm{m} . / \mathrm{sec}$ ) Fx. by 30 min. b) Microperfusion studies- the osmotic water permeability (Pf, $\mu \mathrm{m} . / \mathrm{sec})$ was determined in normal rats $\operatorname{IMCD}(\mathrm{n}=6)$ isolated and perfused by the standart methods. Fx $\left(10^{-7} \mathrm{M}\right)$ was added to the bath fluid. Results: In vivo study showed that the weight decreased from $179 \pm 1.28 \mathrm{~g}$ to $158 \pm 1.5 \mathrm{~g}(\mathrm{p}<0.0001)$; the $\mathrm{Na}^{+}$plasma level decreased from $139.3 \pm 0.78 \mathrm{mEq} / \mathrm{l}$ to $134.9 \pm 0.5 \mathrm{mEq} /(\mathrm{p}<0.0001)$, the $\mathrm{K}^{+}$and the $\mathrm{ADH}$ plasma level remained unchanged. In vitro study- a) the densitometric analysis of the immunobloting essays showed an increase in AQP2 protein abundance of about about $40 \%$, both, in supplied rats (cont-99.6 \pm 5.2 vs Fx 145.6 \pm 16.9 , $\mathrm{p}<0.05$ ), and in membrane fraction extracted from IMCD tubule 


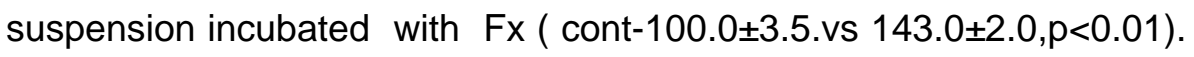

b)

Fx increased the Pf in IMCD in absence of vasopressin from the control period- $7.24 \pm 2.07$ to $F x-15.77 \pm 3.25(p<0.01)$. In summary, our data revealed that, after $\mathrm{Fx}$, weight, and plasma $\mathrm{Na}^{+}$level decreased, the plasma $\mathrm{K}^{+}$and $\mathrm{ADH}$ levels remained unchanged, whereas the AQP2 protein abundance and the water absorption in IMCD increased, leading us to conclude that the direct effect of Fx in the IMCD, could account for the hyponatremia produced by this drug in depressed elderly.

Descriptors: 1.Fluoxetine 2.Collecting kidney tubules 3.Hyponatremia 4.Water 5.Aquaporins 6.Serotonin uptake inhibitors 
Moysés ZP. Efeito de fluoxetina na reabsorção de água pelo rim (dissertação). São Paulo: Faculdade de Medicina, Universidade de São Paulo; 2006. 43p.

A patogenia da hiponatremia decorrente do uso da Fluoxetina em pacientes idosos não está bem definida. Este achado tem sido atribuído a uma secreção inapropriada do Hormônio Antidiurétido (HAD), embora ainda não tenha sido evidenciado um aumento dos níveis plasmático deste hormônio nestes pacientes. Desta forma, este trabalho visa investigar o efeito da Fluoxetina sobre o rim e mais especificamente se ela teria um efeito direto sobre o Ducto Coletor Medular Interno (DCMI) de ratos normais: 1) Estudos in vivo- 10 ratos foram suplementados com aplicações intraperitoniais diárias de $10 \mathrm{mg} / \mathrm{kg}$ de Fluoxetina. Após 10 dias os animais foram sacrificados e o sangue e os rins foram coletados para posterior análise. 2) Estudos in vitro- a) estudos com a técnica de Imunoblotting para avaliar a expressão da proteína da Aquaporina 2 (AQP2) em ratos suplementados e em suspensão de túbulos de DCMI de 10 ratos normais incubados com $10^{-7} \mathrm{M}$ de Fluoxetina por $30 \mathrm{~min}$. b) estudos com microperfusão de segmentos isolados do nefron- a permeabilidade osmótica à água $(\mathrm{Pf}, \mu \mathrm{m} . / \mathrm{sec})$ foi determinada em $\mathrm{DCMl}$ perfundidos de ratos normais $(n=6)$ com a técnica standart, na presença de $10^{-7} \mathrm{M}$ de Fluoxetina. Resultados: 1) Os estudos in vivo mostraram que o peso caiu de $179 \pm 1,28 \mathrm{~g}$ para $158 \pm 1,15 \mathrm{~g}(\mathrm{p}<0,0001)$, o Na plasmático caiu de $139,3 \pm 0,78 \mathrm{mEq} / \mathrm{l}$ para $134,9 \pm 0,5 \mathrm{mEq} / \mathrm{l}(p<0,0001)$ e não houve alterações do $K$ e do HAD 
plasmáticos. 2) Os estudos in vitro-a) a análise densitométrica dos ensaios com imunoblotting mostraram um aumento da expressão da proteína da AQP2 de 40\%, ambos, em ratos suplementados (cont-99,6 \pm 5,2 vs Fx $145,6 \pm 16,9, p<0,05)$ e em frações de membrana da suspensão de túbulos incubados com Fluoxetina (cont-100,0 03,5 .vs 143,0 $\pm 2,0, p<0,01$ ). b) A Fluoxetina aumentou a Pf nos DCMI, na ausência de HAD de 7,24 $\pm 2,07$

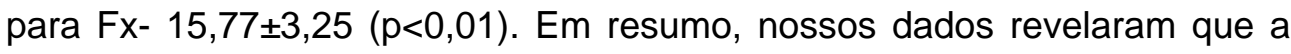
Fluoxetina determinou uma diminuição do peso corporal e do nível plasmático de $\mathrm{Na}$ sem alterar os níveis plasmáticos de K e HAD e ocasionou um aumento da expressão da proteína da AQP2 e um aumento da permeabilidade à água nos DCMI, levando-nos à conclusão de que o efeito direto da Fluoxetina no DCMI, aumentando a reabsorção de água, pode ser responsável pela hiponatremia encontrada nos pacientes idosos com depressão que fazem uso desta droga.

Descritores: 1.Fluoxetina 2.Túbulo coletores renais 3.Hiponatremia 4.Água 5.Aquaporinas 6.Inibidores de captação de serotonina 


\title{
Sumário
}

\begin{abstract}
Resumo
Summary

1 INTRODUÇÃO
\end{abstract}

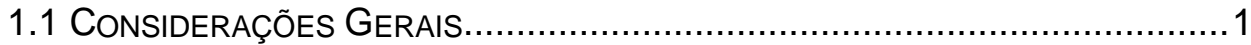

1.2 REABSORÇÃO DE ÁGUA NO DUCTO COLETOR MEDULAR INTERNO..................2

1.2.1 Formação da Medula Hipertônica.............................................2

1.2.2 Ação do Hormônio Antidiurético. ..............................................5

1.3 FLUOXETINA

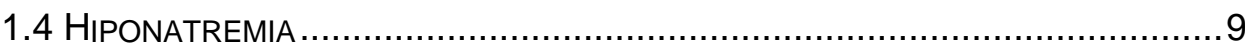

2 OBJETIVO

3 MATERIAL E MÉTODO .....................................................................13

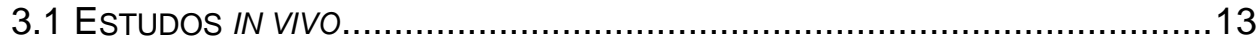

3.2 SUSPENSÃO DE TÚBULOS.............................................................. 14

3.3 EXTRAÇÃO DE PROTEÍNA E WESTERN BLOTTING ...................................15

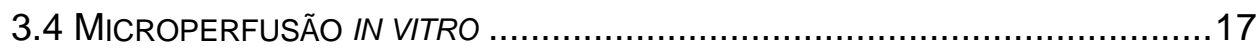

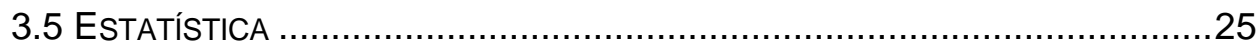

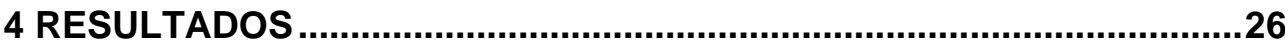

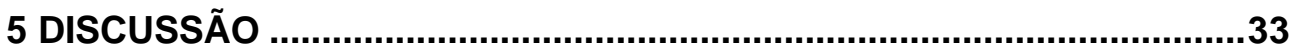

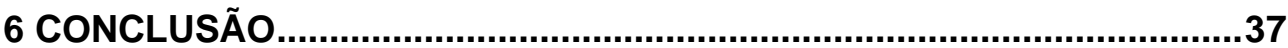

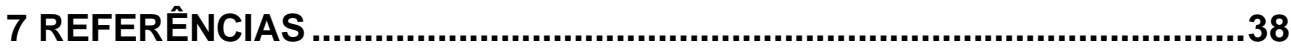

Apêndice 


\section{INTRODUÇÃO}

\subsection{Considerações Gerais}

A fluoxetina é um dos antidepressivos mais usados atualmente para o tratamento de vários distúrbios psíquicos. Esta droga tem a capacidade de inibir seletivamente a recaptação da serotonina. Embora ela já esteja sendo usada há alguns anos, recentemente têm sido relatados casos de hiponatremia, principalmente em idosos, duas a três semanas após o início do tratamento $(1,2)$. A patogenia deste efeito não está bem definida, mas tem sido atribuída a uma secreção inapropriada do hormônio anti-diurético (HAD) (3), que juntamente com uma ingestão de água aumentada, levaria a hiponatremia. Esta secreção inapropriada de HAD não foi ainda evidenciada em pacientes com o uso da fluoxetina. Por outro lado, trabalho experimental (4) com ratos, também não mostrou aumento do HAD plasmático nos animais tratados com fluoxetina e ingestão de água ad libitum, tendo sido sugerido que o efeito hiponatremiante poderia estar ocorrendo em decorrência de uma ação direta sobre o rim, aumentando a sensibilidade do HAD ou mesmo mimetizando a sua ação. 


\subsection{Reabsorção de água no ducto coletor medular interno}

A reabsorção de água que ocorre no último segmento do nefron, o ducto coletor medular interno, é o mecanismo fino pelo qual o rim controla o volume urinário final e é o responsável pela manutenção do balanço de água.

Esta reabsorção de água, neste segmento é controlada por dois grandes fatores: pela formação de uma medula hipertônica e pela ação do HAD.

\subsubsection{Formação da Medula Hipertônica}

O sistema de contracorrente multiplicador inicialmente idealizado e aplicado à medula renal é o mecanismo que explica a adição de solutos à medula com pouco gasto de energia (5). A energia inicial que movimentaria este sistema é dada pelo transporte ativo de $\mathrm{Na}^{+} \mathrm{Cl}^{-}$da luz tubular para o interstício medular na porção ascendente da alça de Henle. Este transporte de $\mathrm{Na}^{+} \mathrm{Cl}^{-}$é que, aumentando a osmolaridade do interstício, promoveria a reabsorção de água no ramo descendente da alça, com conseqüente aumento progressivo da osmolaridade do seu fluido tubular em direção à papila. Este efeito inicial é multiplicado e o gradiente osmótico então criado determinaria maior reabsorção de água no ducto coletor.

Os estudos funcionais da porção espessa da alça de Henle, tanto da região medular, como da região cortical (segmento diluidor), mostraram 
serem eles impermeáveis à água mesmo na presença de hormônio antidiurético (6). Neste segmento, na membrana luminal ocorre uma reabsorção de $\mathrm{Na}^{+}$acoplado a $\mathrm{Cl}^{-}$e $\mathrm{K}^{-}$em um cotransporte $\mathrm{Na}^{+}: \mathrm{K}^{-}: 2 \mathrm{Cl}^{-}$, secundariamente ativo ao transporte de $\mathrm{Na}^{+}$pela $\mathrm{Na}^{+}-\mathrm{K}^{-}$-ATPase na membrana basolateral $(7,8)$. Este transporte ativo propicia um gradiente eletroquímico favorável à entrada da $\mathrm{Na}^{+}$na célula. A passagem de $\mathrm{Na}^{+}$da luz tubular para 0 interstício retirando $\mathrm{Na}^{+}$do fluido filtrado e adicionando-o ao interstício, constitui o chamado efeito unitário do mecanismo de contracorrente multiplicador. Este cotransportador $\mathrm{Na}^{+}: \mathrm{K}^{-}: 2 \mathrm{Cl}^{-}$já foi clonado e seqüenciado (9). A porção espessa ascendente da alça de Henle é uma região importante para o mecanismo de concentração urinária e é o local de ação dos chamados diuréticos de alça, como o furosemide e a bumetanida que se ligando ao sítio do íon $\mathrm{Cl}^{-}$promovem a inibição do cotransportador $\mathrm{Na}^{+}: \mathrm{K}^{-}$ $: 2 \mathrm{Cl}^{-}(10)$

Os ramos finos da alça de Henle, tanto ascendente como descendentes, são formados por um epitélio simples, que repousa sobre uma membrana basal e o citoplasma de suas células é escasso em mitocôndrias. Este padrão morfológico é de um epitélio favorável ao equilíbrio osmótico entre o lúmen e o interstício, e não a um transporte ativo com gasto de energia (11).

O estudo funcional da porção fina descendente da alça de Henle mostra que este ramo é altamente permeável à água e pouco permeável a sódio e a outros solutos, sugerindo que o equilíbrio osmótico com o interstício medular ocorra à custa da reabsorção de água, com conseqüente 
aumento da concentração de cloreto de sódio, uréia e outros solutos no fluido tubular, em direção à papila renal, chegando o fluido tubular a alcançar a osmolaridade de $1200 \mathrm{mOsm} / \mathrm{Kg}$ de $\mathrm{H}_{2} \mathrm{O}$.

A porção fina ascendente da alça de Henle apresenta características opostas às descritas acima para o ramo descendente. Observa-se que a porção ascendente é impermeável à água e altamente permeável a $\mathrm{Na}^{+}$e $\mathrm{Cl}^{-}$, sendo que o movimento transtubular de cloretos deve ocorrer por um mecanismo passivo facilitado.

Nestas condições, a mudança de características de permeabilidade à água e solutos nos ramos finos descendentes e ascendentes permite que o acúmulo de $\mathrm{Na}^{+} \mathrm{Cl}^{-}$, que ocorre na porção descendente da alça de Henle por reabsorção de água, se desfaça, pelo menos em parte, na porção fina ascendente. No entanto, neste segmento ascendente o equilíbrio osmótico com o interstício medular dá-se às custas do efluxo de $\mathrm{Na}^{+} \mathrm{Cl}^{-}$rápido e influxo de uréia mais lento, o que resulta na formação de um fluido tubular com menor concentração de $\mathrm{Na}^{+} \mathrm{Cl}^{-}$que o interstício. Este fluido, agora atingindo a porção espessa ascendente, onde ocorre uma grande reabsorção ativa de $\mathrm{Na}^{+} \mathrm{Cl}^{-}$, ficará cada vez mais hipotônico, sendo que a sua osmolaridade pode atingir valores inferiores a $100 \mathrm{mOsm} / \mathrm{Kg} \mathrm{H} 2 \mathrm{O}$ no início do túbulo distal. Por essa razão, este segmento é chamado de segmento diluidor. Vê-se, portanto, que apenas as características opostas de permeabilidade dos ramos finos, descendentes e ascendentes, proporcionam um meio genial de adicionar soluto $\left(\mathrm{Na}^{+} \mathrm{Cl}^{-}\right)$ao nível da região 
medular interna e de formar um fluido hipotônico à custa, unicamente, da reabsorção ativa de $\mathrm{Na}^{+} \mathrm{Cl}^{-}$da região medular externa (12).

\subsubsection{Ação do Hormônio Antidiurético.}

O conhecimento dos eventos celulares envolvidos na ação do hormônio antidiurético expandiu-se consideravelmente nos últimos anos. $\mathrm{O}$ HAD é um hormônio capaz de induzir alterações estruturais na parede luminal das células principais do ducto coletor medular interno (DCMI) determinando um aumento da permeabilidade a água e a uréia. $\mathrm{O} H \mathrm{HD}$, que evoca a resposta celular é o "primeiro mensageiro", e o seu efeito intracelular é mediado por um "segundo mensageiro", que é produzido como resultado da interação do hormônio com o seu receptor específico. Dois dos mais significantes sistemas de "segundos mensageiros" conhecidos são os sistemas da adenosina monofosfato cíclico $(\mathrm{AMPc})$ e o do $\mathrm{Ca}^{++}$. O HAD exerce seu efeito hormonal estimulando dois tipos de receptores chamados de V1 e V2, sendo que respectivamente utilizam o $\mathrm{Ca}^{++}$e o AMPc como "segundos mensageiros". Estes receptores estão localizados na membrana basolateral da célula principal e quando estimulados determinam alterações bioquímicas intracelulares que por sua vez acarretam modificações na membrana luminal modulando ou regulando a permeabilidade à água.

Quando o HAD se liga ao receptor V2, é ativada uma enzima chamada de adenilciclase. Acredita-se que esta enzima faça parte de um sistema regulador complexo que consistiria de três unidades diferentes: o 
receptor ( $R$ ) a proteina $G$ e uma unidade catalítica ( $A C$ ). Neste modelo a adenilciclase estaria ligada a dois receptores de naturezas opostas: um deles a estimularia (Rs) enquanto o outro a inibiria (Ri), através das unidades reguladoras da proteína G, respectivamente Gs e Gi. Estes receptores ativariam (Gs) ou inibiriam (Gi) a adenilciclase quando o receptor estimulador ou inibidor fossem ocupados respectivamente. O receptor do HAD é o receptor estimulador (Rs), enquanto o receptor ocupado pelos agentes $\alpha-2$ adrenérgicos seria inibidor (Ri) uma vez que estes agentes inibem o transporte de água (13).

A ativação da adenilciclase promoveria a conversão da adenosina trifosfato (ATP) no mediador intracelular 3',5' adenosina monofosfato cíclico (AMPc). A formação do AMPc é o ínicio de uma reação em cascata que termina na incorporação de canais de água na membrana apical: o AMPc ativaria a proteinoquinase $\mathrm{A}(\mathrm{PKA})$ que fosforilaria proteínas do citosol, que por sua vez atuariam em elementos do citoesqueleto celular, tais como microfilamentos e microtúbulos que participariam nos mecanismos pelos quais vesículas citoplasmáticas específicas carregando os canais de água seriam inicialmente inseridas na membrana apical e posteriormente removidas. Neste processo, quando o $\mathrm{ADH}$ estiver presente no plasma, canais de água seriam inseridos na membrana apical (exocitose) enquanto na ausência de HAD, estes canais seriam removidos da membrana apical (endocitose). Este processo, no entanto, pode ser modulado intracelularmente pela atividade da AMPc fosfodiesterase, que converte 0 
AMPc a sua forma inativa a 5'adenosina monofosfato, 5'AMPc, bem como por autacóides, como prostaglandinas, $\mathrm{Ca}^{++}$e proteinoquinase c (PKC).

Recentemente foi descrita a existência de receptores do tipo V1 nas células principais dos túbulos distais (14). Este receptor quando ocupado pelo HAD desencadearia uma reação em cascata da seguinte forma: ativação de uma fosfolipase C (PLC) de membrana que clivaria a fosfatidilinositol bi-fosfato $\left(\mathrm{PIP}_{2}\right)$ em dois segundos mensageiros - o diacilglicerol (DAG) e o inositol-trifosfato (ITP). DAG e Ca++ ativariam PKC enquanto o ITP estimularia a liberação de cálcio das organelas para o citosol. O aumento do cálcio no intracelular e a PKC regulariam a atividade da adenilciclase, exercendo sobre ele um efeito inibitório.

O HAD também estimula uma fosfolipase $A$ de membrana que agindo sobre o ácido aracdônico (AA), produzindo prostaglandina E2 (PGE2) que por sua vez tem um efeito inibitório sobre o adenilciclase, constituindo desta forma um sistema de "feed-back" negativo, modulando a ação do HAD.

A inserção dos canais de água nas paredes luminais do DCMI faz com que a água seja reabsorvida, da luz para o interstício, somente pela ação do gradiente osmótico estabelecido entre a medula renal e a luz tubular, produzindo uma urina concentrada (15).

Estes canais de água, denominados aquaporinas (AQP) fazem parte de uma família de proteínas que facilitam o transporte de água através das membranas celulares de todos os seres vivos. Até o momento já foram descritas onze aquaporinas sendo que oito são expressas no rim, mas 
apenas três nos ductos coletores, a AQP2, a AQP3 e a AQP4. Destas, somente a AQP2 é regulada pelo HAD. As outras duas são expressas constitutivamente, na membrana basolateral (16). A AQP2 já foi clonada e sequenciada e a sua expressão nos DCMI é facilmente detectada pela técnica de Western Blotting. Através desta técnica foi recentemente descritas duas isoformas: uma de 29 kDa e uma outra glicosilada, de 35-50 kDa (17). Esta AQP2 pode se apresentar mais ou menos expressa de acordo com uma inibição ou uma estimulação da cascata do HAD.

\subsection{Fluoxetina}

A Fluoxetina é um agente antidepressivo que aumenta a neurotransmissão serotoninérgica através de uma potente e seletiva inibição da reutilização da serotonina (5-hidroxitriptamina 5-HT) (18). Através de uma n-desmetilação a molécula de Fluoxetina (Figura 1) transforma-se em desmetilfluoxetina que também possui uma ação inibidora na reutilização da serotonina.

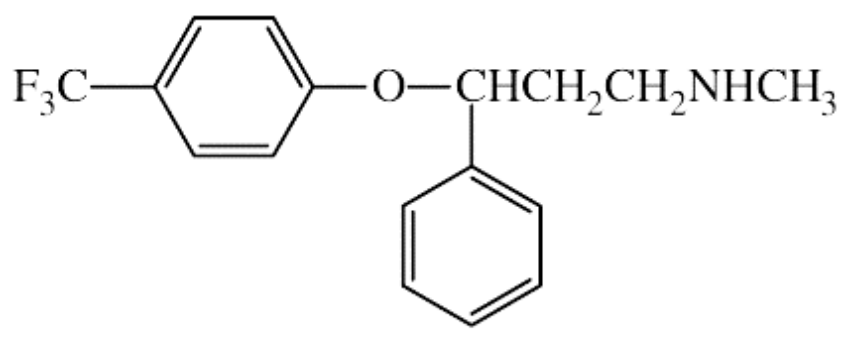

FLUOXETINE

Figura 1. Fórmula estrutural 
Ambos os compostos ligam-se às proteínas plasmáticas e possuem uma meia-vida de eliminação de vários dias, facilitando a manutenção de uma concentração plasmática efetiva durante o tratamento.

A reutilização da serotonina é o fenômeno pelo qual este mediador após estimular os seus receptores na placa pós-sináptica é reaproveitado pelo axônio pré-sináptico. O nível extracelular de serotonina é controlado por um transportador localizado na membrana plasmática do neurônio serotoninérgico e é dependente de $\mathrm{Na}^{+}$e $\mathrm{Cl}^{-}$. Estes transportadores são o alvo dos inibidores em questão (19).

A inibição da reutilização da serotonina propicia uma maior permanência desta droga na fenda sináptica e um aumento da sua capacidade de estimular os seus receptores pós-sinápticos.

Embora o uso destas drogas inibidoras da reutilização da serotonina seja muito difundido atualmente, elas não são isentas de efeitos colaterais (20). Os efeitos colaterais mais comuns são: hiponatremia, sintomas extrapiramidais, sangramentos, arritimias cardíacas, a síndrome da serotonina e anorexia, efeito este utilizado em terapias para redução de peso.

\subsection{Hiponatremia}

A hiponatremia é uma alteração do equilíbrio hidroeletrolítico em que a concentração do sódio plasmático encontra-se abaixo de $135 \mathrm{mEq} / \mathrm{L}$. Ela pode estar associada a uma osmolaridade plasmática normal, 
aumentada ou diminuída. A osmolaridade efetiva ou tonicidade refere-se a contribuição da osmolaridade dos solutos, tais como sódio e glicose, que não podem atravessar com facilidade a membrana celular, induzindo, desta forma, saída de água da célula. As principais situações clínicas que podem estar associadas à hiponatremia estão relacionadas abaixo:

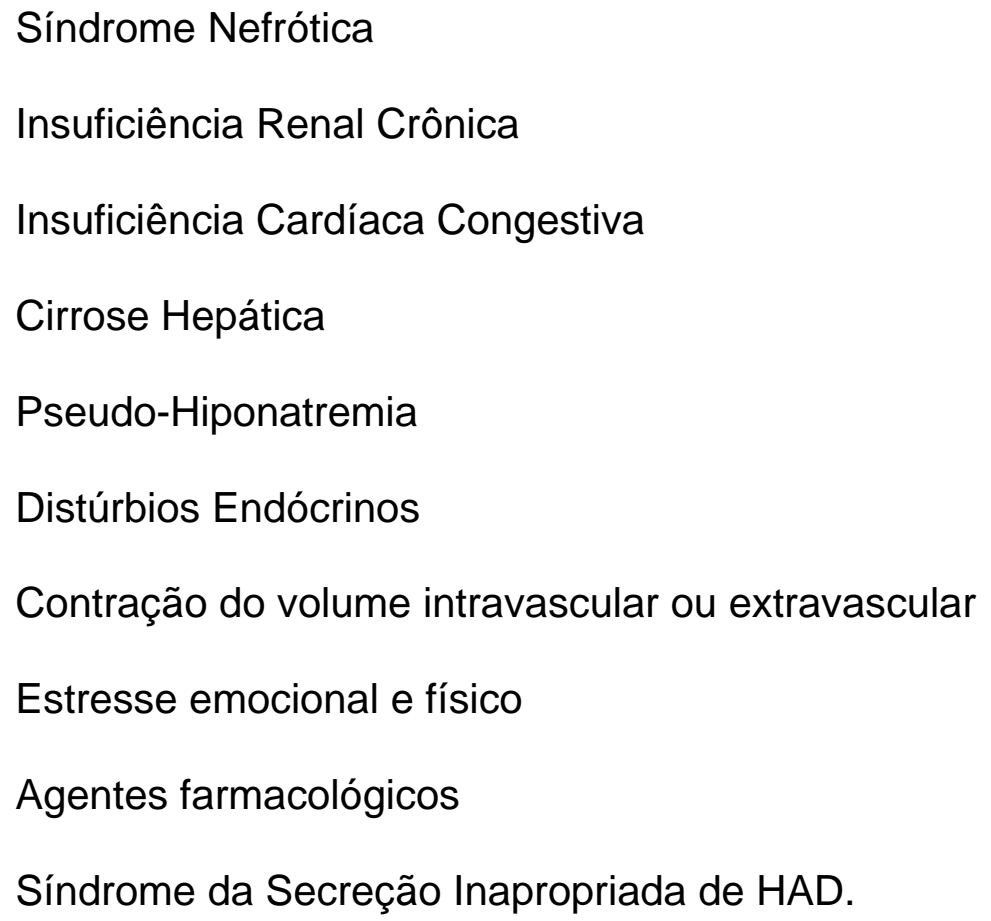

A hiponatremia hipotônica ou dilucional é a forma mais comum de hiponatremia é causada por retenção de água. Quando a ingestão ou retenção de água é superior á capacidade de o rim excretá-la, ocorre uma diluição dos solutos do organismo resultando em hipoosmolaridade com hipotonicidade (osmolaridade plasmática inferior a $275 \mathrm{mOsm} / \mathrm{kg}$ ). Este tipo de hiponatremia ocorre freqüentemente na insuficiência cardíaca congestiva, na depleção do espaço extracelular, na secreção inapropriada do hormônio 
antidiurético e na presença de alguns fármacos como hidroclorotiazida (21), carbamazepina $(22,23)$ e clofibrato $(23,24)$.

A hiponatremia hipertônica ou hiperosmolar está relacionada principalmente com hiperglicemia ou a infusão de manitol (por exemplo em cirurgias urológicas de ressecção trans-uretral de próstata) e cursa com osmolaridade plasmática superior a $290 \mathrm{mOsm} / \mathrm{kg}$.

Por fim, temos a hiponatremia isotônica ou isosmótica, também chamada de pseudo-hiponatremia, que ocorre em pacientes com hiperproteinemia ou hiperlipidemia. A osmolaridade plasmática, em geral está entre 275-290 mOsm/kg.

A hiponatremia hipotônica ou dilucional pode ocorrer por perda renal de sódio, como no uso inadequado de diuréticos, na insuficiência renal pela falta de aldosterona, na nefropatia do "salt-wasting" e recentemente tem sido relatada como decorrente do uso de alguns anticonvulsivantes e antidepressivos. 


\section{OBJETIVO}

A hiponatremia causada pela fluoxetina, apesar de não ser uma ocorrência muito freqüente, pode dificultar o uso desta potente arma terapêutica no tratamento de distúrbios do humor.

O objetivo deste trabalho foi tentar reproduzir experimentalmente os

efeitos dessa droga relatados pela literatura, principalmente quanto à hiponatremia, com o intuito de elucidar o efeito renal deste inibidor da recaptação da serotonina, através das técnicas de microperfusão 'in vitro' de segmento isolado de ductos coletores e de Western Blotting e com estudos em gaiolas metabólicas. 


\section{MATERIAL E MÉTODO}

\subsection{Estudos in vivo}

Nestes experimentos foram utilizados 10 ratos Wistar, machos, com o peso em torno de $180 \mathrm{~g}$, fornecidos pelo Biotério Central da Faculdade de Medicina da Universidade de São Paulo e mantidos no biotério do nosso laboratório até o momento do uso, com dieta normal e livre acesso à água. Os animais foram triados após jejum de 24 horas com a finalidade de serem excluídos os animais que apresentassem a dosagem de uréia sérica acima de 60 mg\% (Método de Crocker modificado - Espectrofotômetro Femto 432C). O sangue era colhido por via caudal e após separação do plasma foram dosados o sódio, o potássio (Fotômetro de Chama - CELM) e a uréia plasmática. Os animais foram pesados nesta ocasião.

Os animais receberam durante 10 dias inoculações intraperitoniais de Fluoxetina na concentração de $10 \mathrm{mg}$ por $\mathrm{kg} /$ peso, mantendo sempre os mesmos horários de aplicação e foram mantidos em dieta normal e livre acesso à água (5). No décimo dia, após 24 horas em jejum, 1 hora após a aplicação da Fx, os animais foram sacrificados. Foi colhido sangue total via 
punção cardíaca para analise do sódio, do potássio e do Hormônio Antidiurético (RIA I ${ }^{125}$, AVP DSL-1800) no plasma e imediatamente após, os rins foram removidos cirurgicamente e colocados na placa de Petri com solução artificial de Ringer $\mathrm{HCO}_{3}$ gelada (Tabela 1). A papila renal foi isolada com o auxilio de pinças de pontas afiladas (Dumont $n^{0} 5$ ) e tesoura oftálmica apropriada, com o auxílio de uma lupa binocular (Nikon) com aumento de 8 a 40 vezes. O material foi imediatamente congelado em nitrogênio líquido e estocado a $-80^{\circ} \mathrm{C}$ para analise da expressão de Aquaporina 2 pela técnica de western blotting.

Tabela 1 - Composição da Solução utilizada

\begin{tabular}{lr}
\hline Substância & Concentração \\
\hline $\mathrm{NaCl}$ & $115,0 \mathrm{mM}$ \\
$\mathrm{NaHCO}_{3}$ & $25,0 \mathrm{mM}$ \\
$\mathrm{CH}_{3} \mathrm{COONa}$ & $10,0 \mathrm{mM}$ \\
$\mathrm{Glicose}$ & $5,0 \mathrm{mM}$ \\
$\mathrm{NaH}_{2} \mathrm{PO}_{4}$ & $1,2 \mathrm{mM}$ \\
$\mathrm{CaCl}_{2}$ & $1,0 \mathrm{mM}$ \\
$\mathrm{KCl}$ & $5,0 \mathrm{mM}$ \\
$\mathrm{MgSO}_{4}$ & $1,2 \mathrm{mM}$ \\
\hline
\end{tabular}

\subsection{Suspensão de Túbulos}

Foram utilizados 10 ratos Wistar machos, com o peso em torno de 180g, fornecidos pelo Biotério Central da Faculdade de Medicina da Universidade de São Paulo e mantidos no biotério do nosso laboratório até o momento do uso, com dieta normal e livre acesso à água. Os animais foram triados com os mesmos procedimentos acima descritos. Após o sacrifício os rins foram removidos cirurgicamente e colocados em placas de Petri com solução artificial de Ringer $\mathrm{HCO}_{3}$ gelada (Tabela 1) e a papila renal foi 
isolada com o auxilio de pinças de pontas afiladas (Dumont $n^{\circ} 5$ ) e estiletes apropriados para cortar os segmentos dissecados sem danifica-los, destacando feixes de tecidos do cortex em direção a papila renal este procedimento foi realizado com o auxilio de uma lupa binocular (Nikon) com aumento de 8 a 40 vezes (25). O material foi separado em dois grupos e incubado por 30 minutos, em solução artificial de Ringer $\mathrm{HCO}_{3}$ (Tabela 1) sendo borbulhada por mistura carbogênica contendo $95 \% \mathrm{O}_{2}$ e $5 \%$ de $\mathrm{CO}_{2}$ à $37^{\circ} \mathrm{C}$, sendo 10 papilas no grupo controle incubado com veículo e 10 papilas no grupo Fluoxetina na concentração de $10^{-7} \mathrm{M}$, imediatamente congelado em nitrogênio líquido e estocado a $-80^{\circ} \mathrm{C}$ para analise de western blotting.

\subsection{Extração de proteína e western blotting}

Amostras das papilas renais de ratos Wistar foram obtidas dos animais tratados com fluoxetina e das suspensão de túbulos, previamente congelado em nitrogênio líquido e estocado a $-80^{\circ} \mathrm{C}$.

A extração de proteína seguiu o protocolo previamente descrito, com pequenas modificações (26). As amostras das papilas renais foram maceradas em nitrogênio líquido, homogeneizadas com um aparelho Potter em solução K-HEPES (Manitol 200 mM, HEPES 80 mM, KOH 41 mM, pH 7,5 e coquetel de inibidores de protease (SIGMA, Saint Louis, Missouri, USA) e centrifugadas a $2000 \mathrm{~g}$ por 15 minutos a $4^{\circ} \mathrm{C}$ para remover núcleo e debris células. Para se obter as frações de membrana, o extrato total 
representado pelo sobrenadante inicial, foi centrifugado a $100,000 \mathrm{~g}$ por 60 minutos a $4^{\circ} \mathrm{C}$ (rotor 50Ti, Beckman Instruments, Palo Alto, CA, USA) o pellet, suspenso em solução K-HEPES a $4^{\circ} \mathrm{C}$. As proteínas presentes foram quantificadas pelo método de Bradford (Bio-Rad Protein Assay Kit), comparando as medidas obtidas para as amostras à curva padrão de albumina bovina lida a $595 \mathrm{~nm}$.

Análises por western blotting foram realizadas utilizando $\sim 5$ ug de proteína desnaturada em tampão de amostra por poço. As amostras foram separada em minigéis SDS-PAGE (SDS-polyacrylamide gel electrophoresis) $12 \%$, de 0,75mm de espessura, em tampão de corrida (Tris $1920 \mathrm{mM}$, Glicina 250 mM, SDS 10\%, pH 8,3 ) utilizando-se 150 V e 70 minutos de corrida. A transferência para membrana de PVDF (Polyvinylidene fluoride, Hybond-P, Amersham Biosciences, Sweden) foi feita com tampão de transferência (Tris 1920 mM, Glicina 250 mM, metanol 20\%), com velocidade constante $150 \mathrm{~V}$ e por 90 minutos. A membrana foi bloqueada com $5 \%$ leite em pó desnatado (Molico) em PBS-T $\left(\mathrm{Na}_{2} \mathrm{HPO}_{4} 80 \mathrm{mM}, \mathrm{NaH}_{2} \mathrm{PO}_{4} 20 \mathrm{mM}\right.$, $\mathrm{NaCl}$ 100mM, Tween 0,1\%, pH 7,5) por 60 minutos, lavada com PBS-T 3 vezes por 10 minutos. A incubação primária foi feita com AQP2 (Aquaporina 2. Santa Cruz Biotechnology, Santa Cruz, CA, USA ) na diluição de 1:500 em solução de PBS-T e Actina (Santa Cruz Biotechnology, Santa Cruz, CA, USA) na diluição de 1:2000 em solução de PBS-T, overnight a $4^{\circ} \mathrm{C}$. A incubação secundária foi realizada com anticorpo anti-goat (Sigma, Saint Louis, Missouri, USA) na diluição de 1:10000 em solução de PBS-T, por 60 minutos. O procedimento de detecção foi o sistema baseado em 
quimioluminescência ECL (Amersham Biosciences, Sweden) por 1 minuto. Revelado em filme de RX (18x24cm - KODAK-MAT G/RA Film), por 8 minutos. A densitometria é feita com o aparelho Image Master VDS (Pharmacia Biotech, Uppsala, Sweden).

\subsection{Microperfusão in vitro}

Os estudos de transporte de água no Ducto Coletor Medular Interno (DCMI) foram realizados utilizando-se a técnica de microperfusão in vitro de segmentos isolados do néfron, descrita para coelhos por Burg e col. em 1966 (27) e adaptada por Rocha e col. em 1991 (28) para o DCMI de ratos Wistar, devido às características próprias deste segmento.

Com esta técnica foram realizados estudos para a determinação da permeabilidade osmótica à água para se caracterizar o transporte de água no DCMI de ratos normais na ausência e na presença de fluoxetina. Para isto foram utilizados ratos Wistar, machos, com o peso em torno de $180 \mathrm{~g}$, fornecidos pelo Biotério Central da Faculdade de Medicina da Universidade de São Paulo e mantidos no biotério do nosso laboratório até o momento do uso, com dieta normal e livre acesso à água. ( $O$ uso de animais neste projeto foi aprovado pela Comissão Ética , cujo protocolo de pesquisa tem o ํo 950/04).

Os animais foram anestesiados por inalação de éter e o rim removido cirurgicamente. Imediatamente após, foi isolada a papila renal, cortando-se uma fatia em forma de cunha perpendicular ao eixo maior do rim 
e colocada em placa de Petri com solução artificial de Ringer $\mathrm{HCO}_{3}$ (Tabela 1) sendo borbulhada por mistura carbogênica contendo $95 \% \mathrm{O}_{2}$ e $5 \%$ de $\mathrm{CO}_{2}$. A microdissecção foi feita com o auxilio de pinças de pontas afiladas (Dumont $n^{\circ} 5$ ) e estiletes apropriados para cortar os segmentos dissecados sem danifica-los, destacando feixes de tecidos do cortex em direção a papila renal. Deste feixe são isolados o IMCD, cuja identificação foi feita pelas características morfológicas e relações anatômicas. Este procedimento foi realizado com o auxilio de uma lupa binocular (Nikon) com aumento de 8 a 40 vezes. O segmento isolado foi transportado para a câmara de perfusão por meio de aspiração com uma pipeta Pasteur com ponta recurvada e adaptada para essa finalidade.

A câmara de perfusão é um disco de acrílico com diâmetro de $6 \mathrm{~cm}$, tendo na parte central uma concavidade de $3 \mathrm{~cm}$ de comprimento por $0,5 \mathrm{~cm}$ de largura, com volume de aproximadamente $1 \mathrm{~cm}^{3}$. O assoalho é composto por uma lamínula de vidro para permitir a visualização dos procedimentos. Esta cavidade é circundada por uma resistência ligada a um termostato externo que mantém a solução do banho a $37^{\circ} \mathrm{C}$. $\mathrm{O}$ banho é borbulhado continuamente por mistura carbogênica contendo $95 \% \mathrm{O}_{2}$ e $5 \%$ de $\mathrm{CO}_{2}$ para manter o pH em torno de 7,4. A câmara de perfusão é adaptada ao prato de um microscópio invertido (Olympus, Tokyo) de modo que todo procedimento podem ser visualizado diretamente com aumentos que variavam de 50 a 400 vezes.

O segmento de DCMI transferido para a câmara de perfusão tinha uma das suas extremidades fixa, por meio de sucção, a uma pipeta 
adaptada ao sistema perfusor e outra extremidade adaptada ao sistema coletor.

O sistema perfusor e o sistema coletor são montados sobre um conjunto de micromanipuladores que permite o seu deslocamento nos três planos ortogonais facilitando o processo de "captura" e fixação do túbulo às micropipetas (Figura 2).

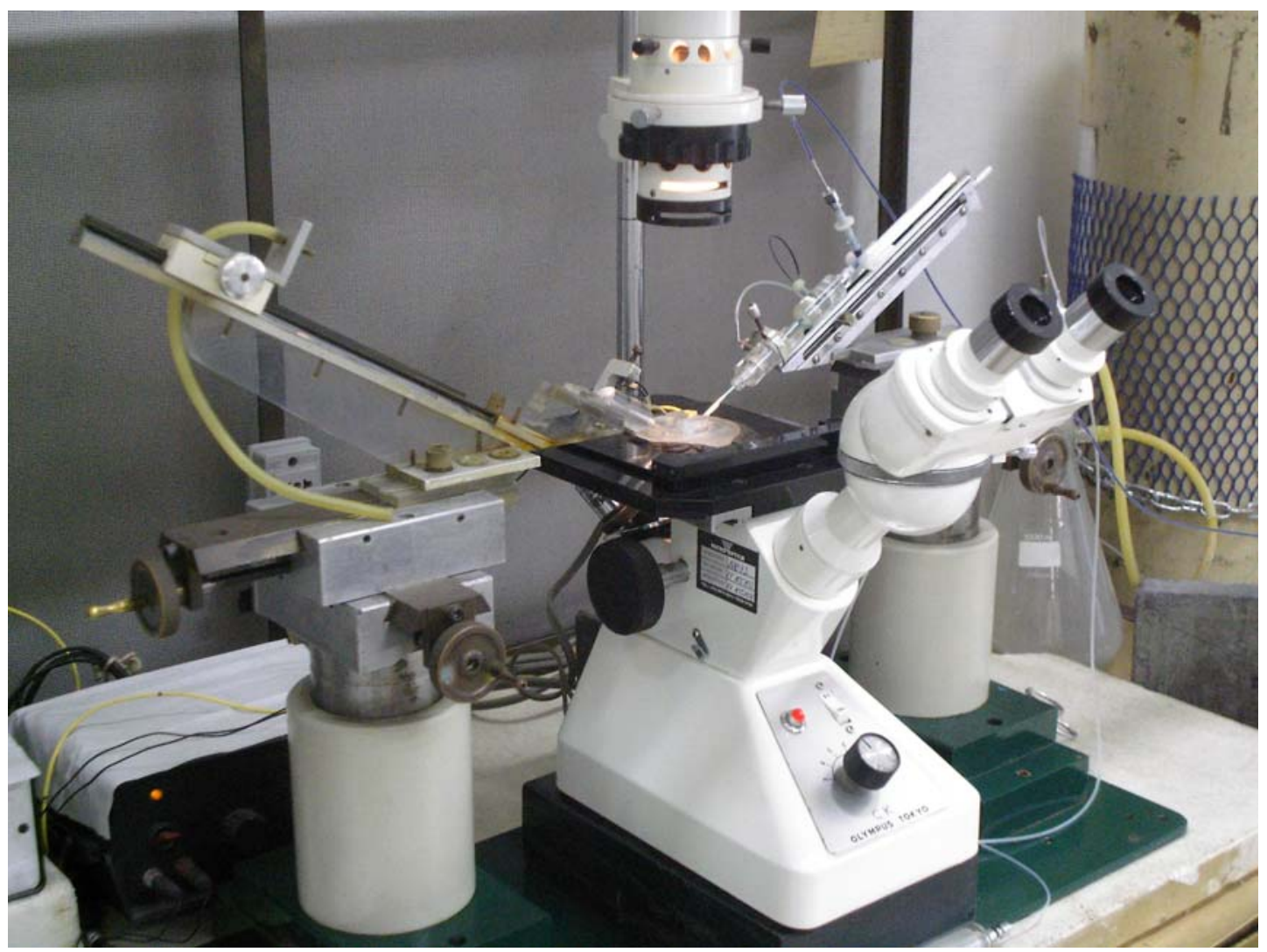

Figura 2. Equipamento de microperfusão

Em cada micromanipulador foram fixadas pipetas confeccionadas com tubos de vidro fornecidos pela "Dumont Scientific Company" (Boomol, Pennsylvania, USA), sendo que as pipetas $A$ ou seguradora e pipeta $C$ ou coletora foram confeccionadas com tubos de 0,064 polegadas de diâmetro interno e as pipetas B ou perfusora e uma pipeta calibrada com volume constante foram confeccionadas com tubos de 0,040 polegadas de diâmetro 
interno. As pipetas foram manufaturadas com a ajuda de uma microforja (Ch.Beaudoin, tipo 35), que processa a extremidade da pipeta previamente estirada por meio de estirador vertical, fabricado em nosso laboratório.

O sistema perfusor consiste de duas pipetas: a pipeta $A$, de diâmetro maior, contendo no seu interior a pipeta $B$, de diâmetro menor e com capacidade de se movimentar concentricamente ao longo da pipeta $A$ por meio de um micromanipulador especialmente construído.

Com a extremidade do segmento dentro da pipeta $A$, movimenta-se a pipeta B para frente introduzindo-a no interior do túbulo. Esta pipeta, previamente preenchida com solução de Ringer $\mathrm{HCO}_{3}$ (Tabela 1) perfunde o túbulo imediatamente após a sua introdução na luz do segmento.

A solução perfusora (Tabela 1) utilizada nas experiências de permeabilidade osmótica era isotônica ao plasma $(295 \pm 5 \mathrm{mOsm} / \mathrm{kg} / \mathrm{H} 2 \mathrm{O})$. A solução de banho tinha a mesma composição que a solução perfusora, porém com o acréscimo de $\mathrm{NaCl}$ para elevar a sua osmolaridade para em torno de $510 \mathrm{mOsm} / \mathrm{kg} / \mathrm{H} 2 \mathrm{O}$, portanto hipertônica em relação à solução perfusora. A osmolaridade foi verificada através do osmômetro (The Advanced Osmometer Instruments) e o pH foi medido através do pHmetro (Iris 7 Tecnow).

Um corante vital atóxico e livre de sódio, FDC (Keystone-Aniline Company), foi adicionado, ao fluido perfusor na concentração máxima de 0,05\% com o objetivo de detectar perfurações e danos celulares que ocasionalmente podem ocorrer no túbulo durante a perfusão. A velocidade de perfusão foi dada pela pressão hidrostática de uma coluna de líquido de 
altura variável em contato com a extremidade distal da pipeta $\mathrm{B}$. A variação da altura da coluna líquida permite uma variação no fluxo da perfusão.

A pipeta $A$ ou seguradora tinha a extremidade com o diâmetro interno entre 40 a 60 micrômetros, com uma constrição de aproximadamente 20 micrômetros localizada a cerca de 100 micrômetros da extremidade, tornando assim a forma de calice, foi siliconizada com óleo Sylgard 184 (Dow Corning).

A pipeta $B$ ou perfusora movimenta-se dentro da pipeta $A$ e tinha a extremidade afilada com 7 a 14 micrômetros de diâmetro.

O sistema coletor é composto pela pipeta $\mathrm{C}$ que coletava o fluido perfundido e pela pipeta calibrada que, quando introduzida no interior da C, recolhe o liquido que percorre a luz do túbulo e se depositava sob o óleo mineral.

A pipeta $\mathrm{C}$ ou coletora foi construída de maneira semelhante à pipeta $A$, porém sem a constrição. A sua extremidade tinha o diâmetro em torno de 50 micrômetros e também foi siliconizada com óleo Sylgard.

A pipeta calibrada tinha forma de ampulheta e capacidade constante. Foi calibrada isotopicamente e utilizada para coletar e transferir, para os frascos de contagem, o liquido já perfundido através do DCMI e coletado sob o óleo na pipeta C coletora.

As extremidades das pipetas A e C são preenchidas com óleo Sylgard com a finalidade de promover um isolamento mecânico e elétrico entre o banho da câmara de perfusão e o fluido, tanto o coletado como o perfundido. 
A medida da permeabilidade osmótica foi feita a partir do cálculo do volume de fluido absorvido $(\mathrm{Vr})$ em resposta a um gradiente osmótico de soluto impermeante.

Este volume absorvido ( $\mathrm{Vr}$ ) foi calculado utilizando-se a seguinte equação:

$$
\mathrm{Vr}=\mathrm{Vi}-\mathrm{Vc}
$$

Onde $\mathrm{Vr}$ tem as unidades de nanolitros por minuto, Vi é o volume infundido em nanolitros por minuto e Vc é o volume coletado nas mesmas unidades.

O volume coletado foi medido diretamente através da pipeta coletora, de volume constante e conhecido. Dividindo-se pelo tempo de coleta obtínhamos o volume coletado por minuto. O volume infundido foi calculado utilizando-se as seguintes equações:

$$
\begin{aligned}
& V i . C i n=V c . C c \\
& V i=V c(C c / C i n)
\end{aligned}
$$

Sendo Cc e Cin as contagens por minuto de Inulina ${ }^{14} \mathrm{C}$ (Amersham Life Science International and New England Nuclear) coletada e infundida, respectivamente. $O$ isotopo foi adicionado na solução de perfusão na concentração final de $25-100 \mathrm{cpm} / \mathrm{nl}$.

Sabe-se que a Inulina não é reabsorvida e nem secretada pelos túbulos renais, sendo sua concentração conseqüência da sua maior ou menor diluição na luz tubular. A concentração de Inulina radioativa na solução perfusora (Cin), isto é, na solução infundida foi obtida tomando- 
seum volume conhecido, retirado diretamente da pipeta B, logo após o término da experiência e verificando-se o número de contagens por minuto.

O volume de água reabsorvido (Jv) foi calculado pela fórmula:

$$
J v=(V i-V c) / L
$$

Onde é L o comprimento do túbulo.

Utilizamos para o cálculo da permeabilidade osmótica a seguinte equação descrita por Bois e col.,1976 (29).

$\mathrm{Pf}=1 /\left(\mathrm{RTA} . \mathrm{Cb}^{2}\right) \cdot\{\mathrm{Cb}(\mathrm{Vi}-\mathrm{Vc})+\mathrm{Ci} \cdot \mathrm{Vi}[\ln (\mathrm{Cb}-\mathrm{Ci}) \cdot \mathrm{Vi}-\ln (\mathrm{Cb} \cdot \mathrm{Vc}-\mathrm{Ci} \cdot \mathrm{Vi})]\}$

Onde $\mathrm{Cb}$ e Ci são as osmolaridade do banho e do fluido de perfusão inicial, respectivamente, $\mathrm{R}$ é a constante dos gases, $\mathrm{T}$ é a temperatura absoluta e A é a área. A área foi calculada através da equação- Di $x L \times \pi$, onde Di é o diâmetro interno e L é o comprimento do túbulo. Estas medidas foram feitas utilizando-se uma ocular com escala graduada e o resultado foi expresso em $10^{-4} \mathrm{~cm}^{2}$. Os resultados foram expressos em $10^{-5} \mu \mathrm{m} / \mathrm{seg}$.

O banho era trocado a cada 10 minutos para reduzir o efeito da evaporação e conseqüentemente o aumento do gradiente osmótico.

Em cada período foram efetuadas, no mínimo 3 coletas. As amostras coletadas eram imediatamente transferidas para os frascos de contagem apropriados e com $0,5 \mathrm{ml}$ de água e em seguida era adicionado 0 líquido de cintilação (1000 ml Triton X-100 , 2000ml Tolueno (Merck), 0,206g POPOP e 16,50g PPO (SIGMA, Saint Louis, Missouri, USA )).

A radiação presente nas amostras era contada em um contador para radiação beta (Packard Tricarb 1600TR, Downers Grove,IL) utilizando um canal para carbono ${ }^{14} \mathrm{C}$. As contagens eram feitas por 2 minutos duas 
vezes. O número de contagens por minuto presente nas amostras foi sempre maior que 20 vezes a contagem de fundo.

Foram estudados 8 segmentos, de permeabilidade osmótica no IMCD de ratos na presença de Fluoxetina adicionados ao banho na concentração de $10^{-7} \mathrm{M}$. 


\subsection{Estatística}

Os dados são expressos em média ${ }^{ \pm}$erro padrão. Para análise estatística dos dados obtidos utilizamos o teste "t" de Student pareado (nível de significância de 5\%). Nos experimentos de microperfusão, em cada período o valor apresentado representa a média de 3 a 4 coletas. A análise estatística dos valores de $\mathrm{Na}, \mathrm{K}$ e peso dos animais foi feita utilizando-se $\mathrm{o}$ mesmo teste descrito acima. Para analisar a expressão de AQP2 pelo método de western blot, foi utilizado teste de Mann-Whitney. Valores de p $<0.05$ foram considerados significantes. Toda a análise foi realizada usando o GraphPad Prism Program version 3.03 (GraphPad Software, San Diego, California). 


\section{RESULTADOS}

\section{Estudo in vivo}

Estes experimentos foram realizados com animais normais, nos quais foi injetado intraperitonealmente uma solução de soro fisiológico com fluoxetina na dosagem de10 $\mathrm{mg}$ por $\mathrm{kg} /$ peso. No período controle, após a triagem, os animais eram pesados e as dosagens plasmáticas obtidas na triagem de sódio e potássio foram consideradas pertencentes a este período.

Peso corpóreo - No período controle a média do peso dos animais foi de

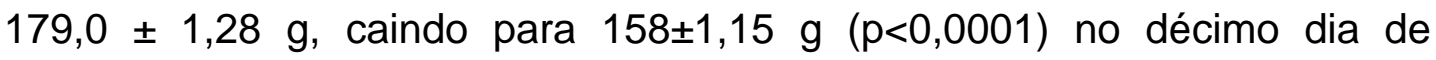
tratamento (Tabela 2, Figura 3).

Tabela 2 - Efeito da Fluoxetina sobre o Peso dos animais

\begin{tabular}{l|cccccccccc|c}
\hline Ratos & 1 & 2 & 3 & 4 & 5 & 6 & 7 & 8 & 9 & 10 & X \pm ep \\
Controle & 182 & 187 & 172 & 175 & 181 & 179 & 177 & 180 & 178 & 179 & $179,0 \pm 1,28$ \\
Fx & 160 & 166 & 154 & 153 & 159 & 157 & 158 & 160 & 156 & 158 & $158,1 \pm 1,15^{\star}$ \\
\hline
\end{tabular}

Fx-Fluoxetina; * $\mathrm{p}<0,0001$, comparados com o controle 


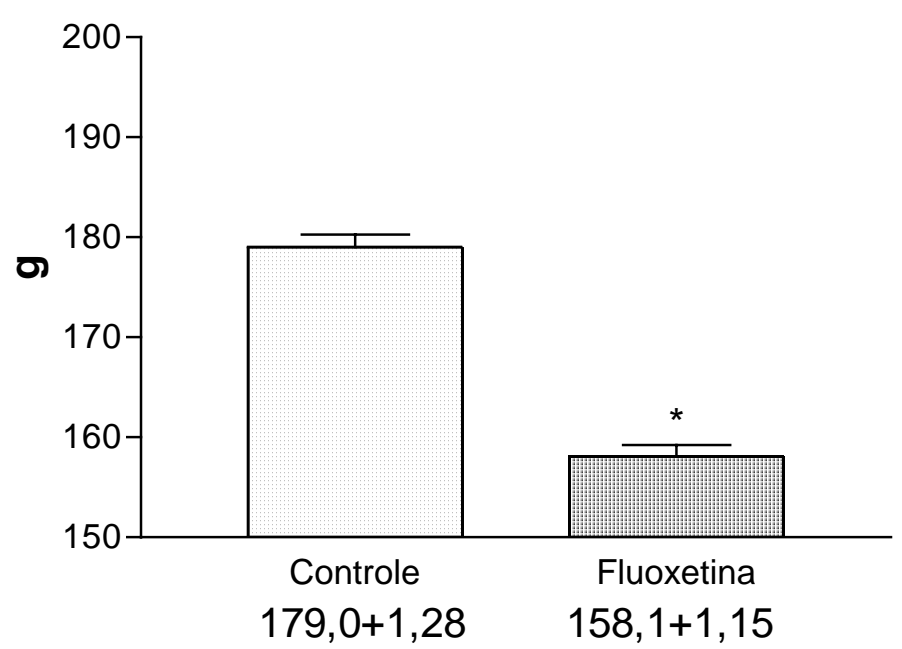

Figura 3. Efeito da Fluoxetina sobre o peso dos animais ${ }^{*} \mathrm{p}<0,0001$, comparados com o controle

Sódio plasmático- Os níveis plasmáticos de $\mathrm{Na}$ tiveram uma significante redução quando comparados pré e pós tratamento. A média das dosagens de $\mathrm{Na}$ dos animais controle antes do tratamento $139,3 \pm 0,7 \mathrm{mEq} / \mathrm{l}$ e após o tratamento com Fx reduziu para 134,9 $0,5 \mathrm{mEq} / \mathrm{l}(\mathrm{p}<0,0001)$ (Tabela 3 , Figura 4).

Potássio plasmático- As dosagens de potássio plasmático dos períodos controle e com fluoxetina não mostraram diferenças significantes $(5,37 \pm 0,1 \times 5,04 \pm 0,2$, respectivamente) (Tabela 3, Figura 4). 


\begin{tabular}{|c|c|c|c|c|}
\hline \multirow[b]{2}{*}{ RATOS } & \multicolumn{2}{|c|}{$\mathrm{Na}^{+}$} & \multicolumn{2}{|c|}{$\mathrm{K}^{+}$} \\
\hline & Controle & Fluoxetina & Controle & Fluoxetina \\
\hline 1 & 143 & 135 & 4.8 & 4.3 \\
\hline 2 & 137 & 134 & 5.6 & 5.7 \\
\hline 3 & 138 & 135 & 5.0 & 4.8 \\
\hline 4 & 141 & 136 & 5.8 & 4.4 \\
\hline 5 & 138 & 136 & 5.0 & 4.8 \\
\hline 6 & 137 & 137 & 5.4 & 5.6 \\
\hline 7 & 138 & 135 & 5.1 & 5.0 \\
\hline 8 & 140 & 132 & 6.0 & 4.4 \\
\hline 9 & 142 & 134 & 5.6 & 4.4 \\
\hline$X_{ \pm} E P$ & $139,3 \pm 0,7$ & $134,9 \pm 0,5^{*}$ & $5,37 \pm 0,1$ & $5,04 \pm 0,2$ \\
\hline
\end{tabular}

$\mathrm{Na}^{+}$e $\mathrm{K}^{+} \mathrm{mEq} / \mathrm{l} ;{ }^{*} \mathrm{p}<0,0001$, comparados com controle

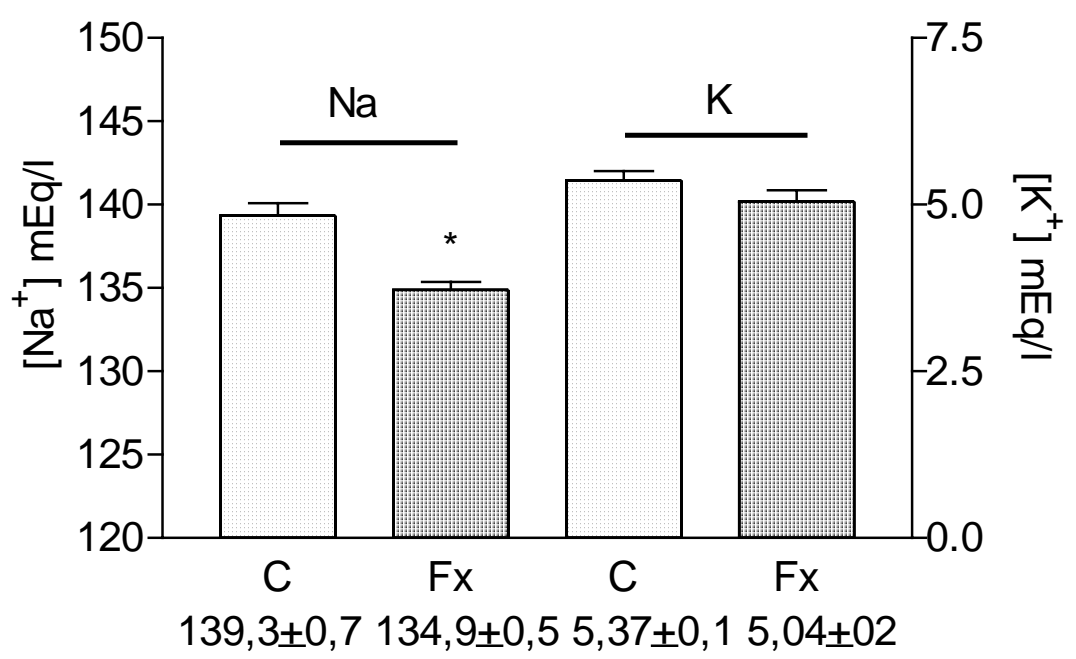

Figura 4. Efeito da Fluoxetina sobre o Sódio e o Potássio plasmático ${ }^{*} \mathrm{p}<0,0001$, comparados com controle 
HAD plasmático- O hormônio antidiurético foi dosado em apenas 4 animais, por insuficiência de material, colhido no décimo dia. Estas dosagens foram : $14 \mathrm{pg} / \mathrm{ml}, 12 \mathrm{pg} / \mathrm{ml}, 13 \mathrm{pg} / \mathrm{ml}$ e $16 \mathrm{pg} / \mathrm{ml}$ correspondendo aos ratos ํㅜ 1,3,4 e 5 . O método utilizado tem como padrão de valor normal até $14 \mathrm{pg} / \mathrm{ml}$. Desta forma, estes animais não apresentaram aumento dos níveis séricos de HAD.

Analises por Western Blot - Neste grupo foram realizados dois tipos de experimento: a) animais tratados com fluoxetina $10 \mathrm{mg} / \mathrm{kg} / \mathrm{rato}$. Destes animais foram retirados os rins e as frações de membrana das papilas renais foram analisadas por western blot. Estas análises demonstraram bandas especificas de peso molecular 29 e $35-50 \mathrm{kD}$ para aquaporina 2 (AQP2). Essas bandas foram detectadas nas papilas dos animais que foram tratados com fluoxetina e nas incubações de suspensão de túbulos. Nos animais tratados com Fluoxetina foi detectado uma intensidade maior das bandas, quando comparados com os animais controle, média de 4 animais controle $99,6 \pm 5,17$, maior intensidade da banda na média de 10 animais tratados com Fluoxetina 145,6 \pm 16,93 (Figura 5). b) Nas incubações de suspensão de túbulos foram detectadas maior intensidade das bandas, quando comparamos a incubação controle, média de 4 incubações controle 100,0 \pm 3,52, ocorreu uma maior intensidade da banda na média de 5 incubações tratadas com Fluoxetina 143,0 $\pm 2,0$ (Figura 6) 


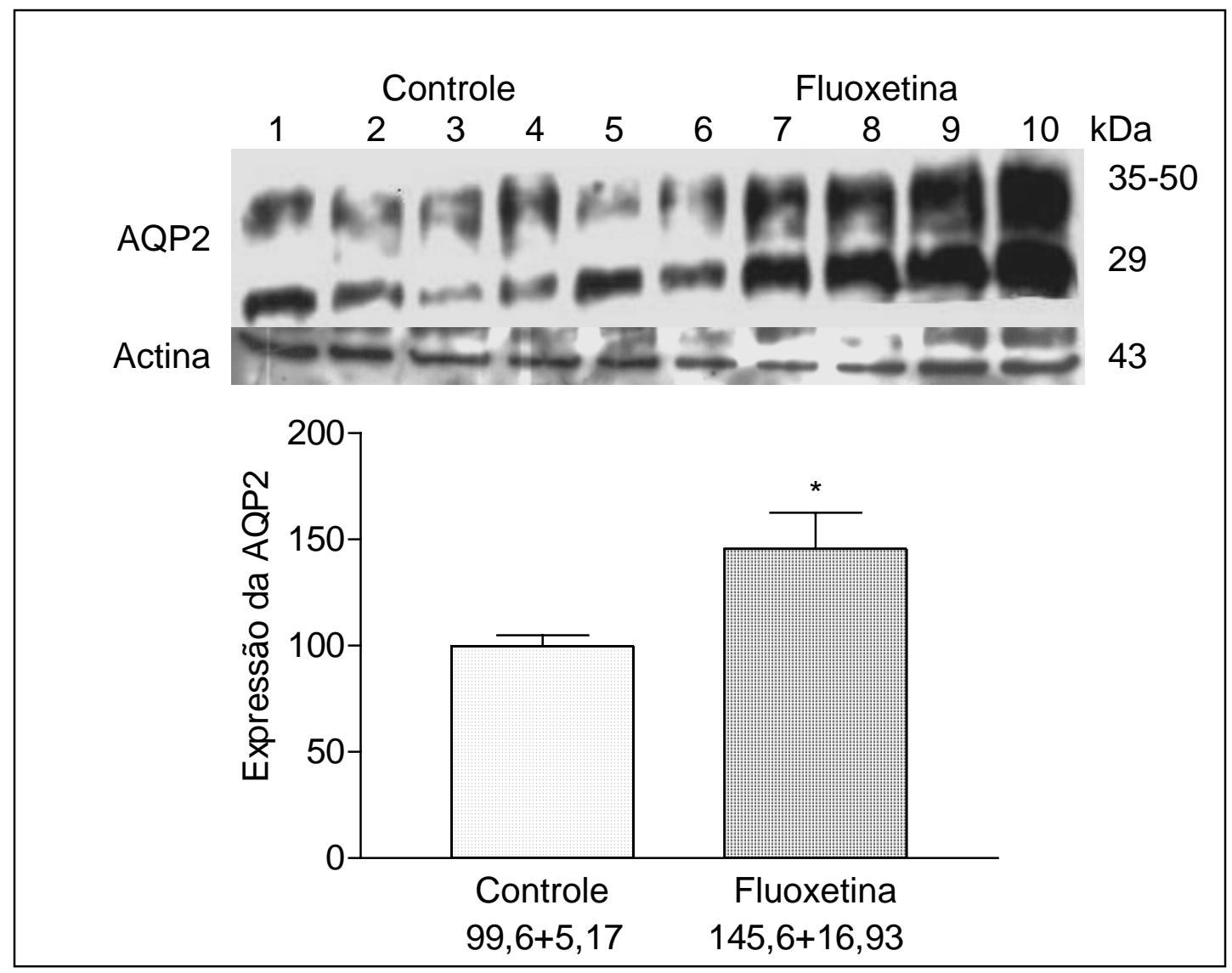

Figura 5. Análises por western blot .dos animais tratados com Fluoxetina (Fx)

Controle $n=4$; Fluoxetina $n=10 ;{ }^{*}, p<0,05$, comparados com Controle ( C ) 


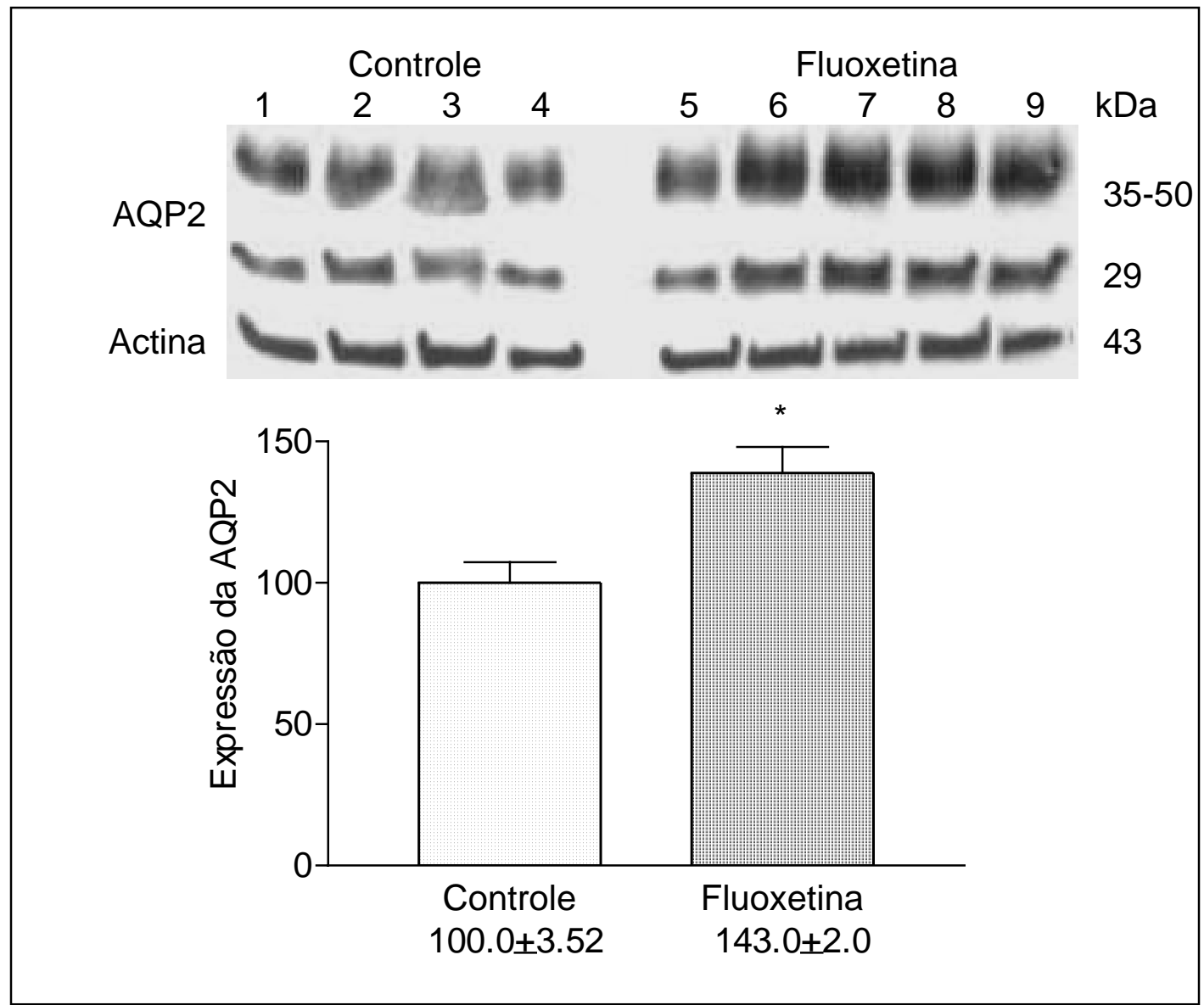

Figura 6. Análises por western blot das incubações de suspensão de túbulos

Controle $n=4$; Fluoxetina $n=5 ;{ }^{*}, p<0,001$, comparados com controle 


\section{Microperfusão in vitro}

Nesta série de experimentos, utilizando-se a técnica de microperfusão de segmentos isolados perfundidos in vitro, foi determinada a permeabilidade osmótica ( $\mathrm{Pf} \times 10^{-5} \mu \mathrm{m} / \mathrm{s}$ ) de DCMls de ratos normais, nos períodos controle $(C)$, experimental $(F x)$ e recuperação $(R e c)$ na ausência de HAD. A fluoxetina $(F x)$ adicionada ao banho na concentração de $10^{-7} \mathrm{M}$ determinou um aumento estatisticamente significante da permeabilidade à água. No período controle foi de $7,24 \pm 2,07$, aumentando para $15,77 \pm 3,25$ $(p<0,01)$ e recuperando-se para 6,21 $\pm 1,13$ após a retirada da droga (Figura 7).

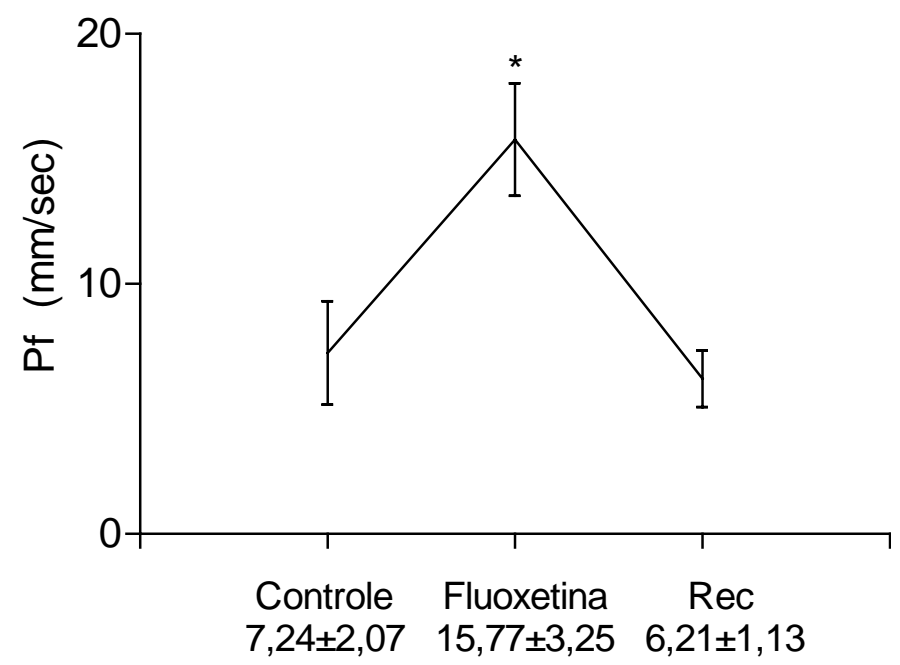

Figura 7. Efeito da Fluoxetina sobre a permeabilidade osmótica em ratos wistar Normais $(n=8) ;{ }^{*}, p<0,01$ para Fx vs. C e Rec 


\section{DISCUSSÃO}

A manutenção do balanço de água pelo organismo é mantida pela quantidade de água ingerida, regulada pelo centro da sede e pela quantidade de água excretada, regulada pelo rim. Para esta manutenção, os mamíferos terrestres necessitam eliminar urina com osmolaridade superior à do plasma, isto é, formar uma urina concentrada em solutos.

A eliminação de urina concentrada é conseqüência da reabsorção de água no ducto coletor medular interno na presença de um gradiente osmótico entre a medula e a luz tubular e sobre a ação do HAD, aumentando a sua permeabilidade á água.

Alterações no mecanismo de reabsorção de água neste último segmento do néfron, ou pelo aumento ou pela diminuição da reabsorção, pode gerar alterações do balanço de água no organismo, levando a patologias tais como hiponatremias ou hipernatremias. Estas alterações, por exemplo, podem ser decorrentes do efeito de drogas que interferem com a ação do HAD.

Recentemente foram relatados casos de antidepressivos do tipo dos inibidores da recaptação da serotonina que têm ocasionado 
hiponatremia do tipo dilucional pelo aumento da reabsorção de água $(21,24,30)$. Este aumento de reabsorção tem sido atribuído a uma secreção inapropriada do HAD, mas este efeito ainda não foi determinado.

O presente estudo teve como objetivo estudar o efeito destas drogas, especificamente a fluoxetina, uma vez que não está caracterizado o seu efeito no ducto coletor medular interno.

Estudos in vivo- Neste grupo foram estudados animais nos quais a Fluoxetina foi administrada por via intraperitoneal na dosagem de $10 \mathrm{mg} / \mathrm{kg} /$ rato (4). Nestes animais o peso foi medido no período controle e no fim do experimento, antes do sacrifício dos animais, bem como foram dosados os níveis séricos do sódio e do potássio. O nível de HAD só foi dosado no final do experimento em 4 animais.

Peso-Os resultados encontrados mostraram uma redução do peso dos animais ao longo dos 10 dias de uso da Fluoxetina (Tabela-2). È conhecido que esta droga é largamente utilizada como coadjuvante na terapia de redução de peso em pacientes obesos (31). Como os animais perderam peso neste período, estes resultados podem ser decorrentes deste efeito anorexígeno, mas pouco se sabe sobre isto em animais de experimentação (32), no entanto foi referido por Marar e Amico (4).

Sódio Plasmático- Os valores do sódio plasmático encontrados no período controle foi de 139,3 \pm 0,7 mEq/l e o resultado após 10 dias de uso da Fluoxetina foi de $134,9 \pm 0,5 \mathrm{mEq} / \mathrm{l}$. Estes dados, que estão na Tabela 3 e na Figura 5, evidenciam claramente que houve uma queda para valores considerados como uma hiponatremia (igual ou abaixo de $135 \mathrm{mEq} / \mathrm{l}$ ). Este 
efeito hiponatremiante é fartamente relatado na literatura em pacientes $(1,2,3,24,33,34)$, mas muito pouco referido em estudos experimentais com animais. Todas as referências descrevendo casos clínicos aventam a hipótese de esta hiponatremia ser decorrente de uma secreção inapropriada do HAD, mas nenhum trabalho apresenta os níveis de HAD no plasma. Marar e Amico fizeram as dosagens de HAD plasmático em ratos e não encontraram diferenças entre o período controle e o experimental e sugerem que a causa da hiponatremia poderia ser um aumento da sensibilidade do rim ao efeito do HAD (4).

Potássio Plasmático- Não foram observadas alterações nos níveis plasmáticos do potássio (Tabela 3 Figura 5), após o uso da fluoxetina.

HAD Plasmático- Embora as dosagens de HAD não tenham sido feita em todos os animais (4 dosagens), não foi detectado um aumento dos níveis plasmáticos deste hormônio. Estes achados estão em conformidade com os dados encontrados por Marar e Amico (4).

Expressão da Aquaporina 2- A expressão da AQP2 foi determinada nos ductos coletores de ratos previamente inoculados com fluoxetina no peritôneo e nos ductos coletores de ratos normais incubados com o antidepressivo. Os resultados encontrados, nos dois grupos, mostraram que houve um aumento da expressão do canal de água, confirmando os dados encontrados nos experimentos de microperfusão. Estes resultados encontrados confirmam, por outra metodologia, os resultados de nossos estudos de microperfusão. 
Perfusão in vitro- A dose utilizada de Fluoxetina foi de $10^{-7} \mathrm{M}$, após um projeto piloto que mostrou ser esta a menor dose que apresentava reprodutibilidade dos resultados. Nos estudos in vivo, foi adotada a dose de $10 \mathrm{mg} / \mathrm{kg} /$ rato intraperitoneal (4). Neste grupo de experimentos foi determinada a permeabilidade osmótica do ducto coletor medular interno na ausência de HAD. No período controle a $\operatorname{Pf}\left(\times 10^{-5} \mu \mathrm{m} / \mathrm{s}\right)$ foi de $7,24 \pm 2,07$. Após a adição de $10^{-7} \mathrm{M}$ de Fluoxetina ao banho a Pf subiu para $15,77 \pm 3,25$ $(p<0,01)$ mostrando um claro efeito de aumentar a permeabilidade à água e evidenciando um efeito "HAD-like". No período de recuperação, após a retirada da fluoxetina a permeabilidade se recuperou para $6,21 \pm 1,13$. Este efeito mostra uma ação direta da Fluoxetina sobre o DCMI, como havia sido sugerida por Marar e Amico em um dos poucos trabalhos experimentais com ratos encontrados na literatura (4). 


\section{CONCLUSÃO}

Os dados encontrados neste experimento confirmam a hipótese de que a hiponatremia associada ao uso de fluoxetina tem origem na diluição plasmática ocasionada por um aumento da reabsorção de água no ducto coletor, como foi observado pelas experiências de microperfusão. $O$ aumento da expressão da AQP2 nos ductos coletores que estiveram em contacto com a fluoxetina confirmam os dados in vitro. Estes dados, juntamente com a ausência de elevação do HAD plasmático, mostram que o efeito direto da fluoxetina no ducto coletor é a causa primária deste defeito e não uma secreção inapropriada do HAD, como os trabalhos de literatura sugerem. No entanto, não podemos deixar de considerar a possibilidade da

existência de outros fatores que possam coexistir e colaborar para o aparecimento desta hiponatremia. 


\section{REFERÊNCIAS}

1. ten Holt WL, van Iperen CE, Schrijver G and Baterlink AK. Severe hyponatremia during therapy with fluoxetine. Arch Intern Med. 1996;156:681-682.

2. Girault C, Richard JC, Chevron V, Goulle JP, Droy JM, Bonmarchand G, Leroy J. Syndrome of inappropriate secretion of antidiuretic hormone in two elderly women with elevated serum fluoxetine. J Toxicol Clin Toxicol. 1997;35:93-95.

3. Lane RM. SSRIs and hyponatraemia.Br J Clin Pract. 1997;51:144-147.

4. Marar IE, Amico JA. Vasopressin, oxytoxin, corticotrophin-releasing factor, and sodium response during fluoxetine administration in the rat. Endocrine. 1998;8:13-18.

5. Stephenson JL. Concentration of urine in a central core model of the renal counterflow system. Kidney Int .1972;2:85-94. 
6. Burg MB,Green N. Function of the thick ascending limb of the Henle's loop. Am J Physiol. 1973;224: 659-668.

7. Rocha AS, Kokko JP. Sodium chloride and water transport in the medullary thick ascending limb of Henle. J Clin Invest . 1973;52:612-624.

8. Sands JM, Knepper M, Spring KR. Na-K-Cl cotransport in apical membrane of rabbit renal papillary surface epithelium. Am J Physiol. 1986;251:F475-480.

9. Obermüller N, Kunchaparty S, Ellison DH, Bachmann S. Expression of the $\mathrm{Na}-\mathrm{K}-2 \mathrm{Cl}$ cotransporter by macula densa and thick ascending limb cells of rat and rabbit nephron. J Clin Invest. 1966;98:635-640.

10. Friedman PA, Hebert SC. Site and mechanism of diuretic action. In Diuretic Agents editado por Seldin D e Giebisch G. Academic Press. 1997.

11. .Jamison RL, Bennett CM, Berliner RW. Countercurrent multiplication by the thin loops of Henle. Am J Physiol. 1967;212:357-366.

12. Kokko JP, Rector FC Jr. Countercurrent multiplication system without active transport in inner medulla. Kidney Int. 1972;2:214-223. 
13. Abramow M, Beauwens, Cogan E. Cellular events in vasopressin action. Kidney Int. 1987;323(suppl 21):S-56-66.

14. Han JS. Dual actions of vasopressin and oxytocin in regulation of water permeability in terminal collecting duct. Am J Physiol. 1993;265:F26-34.

15. Nielsen S, Kwon TH, Christensen BM, Promeneur D, Frokiaer J, Marples D. Physiology and pathophysiology of renal aquaporins. J Am Soc Nephrol. 1999;10:647-663.

16. Nielsen S, Frokler J, Marples D, Kwon T, Agre P and Knepper MA. Aquaporins in the kidney: from molecules to medicine. Physiol Rew. 2002;82:205-244.

17. Nielsen S, DiGiovanni SR, Christensen El, Knepper MA and Harris HW. Cellular and subcellular immunolocalization of vasopressin-regulated water channel in rat kidney. Proc Natl Acad Sci U S A. 1993;15: 1166311667.

18. Benfield P, Heel RC and Lewis SP. Fluoxetine. A rewiew of its pharmacodynamic and pharmacokineties and therapeutic efficacy in depressive illness. Drugs. 1986;31:481-508.

19. Quick MW. Regulating the conducting states of mammalian serotonin 
transporter. Neuron. 2003;40:537-549.

20. Goldberg R J. Selective Serotonin Reuptake Inhibitors. Arch Fam Med. $1998 ; 7: 78-84$

21. Spital A. Diuretic-induced hyponatremia. Am J Nephrol. 1999;19:447-452.

22. Meinders AE, Cejka V, Robertson GL. The Antidiuretic action of carbamazepine in man. Clin Sci Mol Med. 1974;47:289-299.

23. Rado JP, Juhos E, Sawinsky I.Dose-response relations in drug-induced inappropriate secretion of $\mathrm{ADH}$ : effects of clofibrate and carbamazepine. Int J Clin Pharmacol Biopharm. 1975;12:315-319.

24. Moses AM, Miller M. Drug-induced dilutional hyponatremia. N Engl J Med. 1974;291:1234-1239.

25. Shaw S, Marples D. A rat kidney tubule suspension for the study of vasopressin-induced shuttling of AQP2 water channels. Am J Physiol. 2002;283:F1160-F1166.

26. Burnette WN. "Western blotting": electrophoretic transfer of proteins from sodium dodecyl sulfate--polyacrylamide gels to unmodified nitrocellulose 
and radiographic detection with antibody and radioiodinated protein $A$. Anal Biochem. 1981;112:195-203.

27. Burg M, Grantham J, Abramow M, Orloff J. Preparation and study of fragments of single rabbit nephrons. Am J Physiol. 1966;210:1293-1298.

28. Rocha AS, Kokko JP. Permeability of medullary nephron segments to urea and water: Effect of chlorpropamida on water and urea transport in the inner medullary collecting duct. Kidney Int. 1991;39:79-86.

29. Bois DR, Verniory A, Abramow M..Computation of the osmotic water permeability of perfused tubule segments. Kidney Int. 1976;10:478-479.

30. Neafsey PJ. Thiazides and selective serotonin reuptake inhibitors can induce hyponatremia. Home Healthc Nurse. 2004;22:788-90.

31. Halford Jc,Harrold Ja, Lawton Cl, Blundell Je. Serotonin (5-Ht) Drugs: Effect on appetite expression and use for the treatment of obesity. Curr Drug Targets. 2005;6:201-13.

32. Bock N, Quentin DJ, Huther G, Moll GH, Banachewsky T, Rothenberger A.Very early treatmente with fluoxetine and reboxetine causing longlasting change of the serotonin but not the noradrenaline transporter in the frontal cortex of rats. World J Biol Psychiatry. 2005;6:107-112. 
33. Twardowyschy CA, Bertolucci CB, Gracia CM, Brandão MA.Severe hiponatremia and syndrome of inappropriate secretion of antidiuretic hormone (SIADH) associated with fluoxetine: case report. Arg Neuropsiquiatr. 2006;64:142-145.

34. Liu BA, Mittmann N, Knowles SR, Shear NH. Hyponatremia and the syndrome of inappropriate secretion of antidiuretic hormone associated with the use of selective serotonin reuptake inhibitors: a review of spontaneous reports. Can Med Ass J. 1996;155:519-527. 